\title{
WHAT HAPPENS NEXT? CURRENT KNOWLEDGE AND CLINICAL PERSPECTIVE OF PREGNANCY DENIAL AND CHILDREN'S OUTCOME
}

\author{
Donatella Kettlewell ${ }^{1}$, Maud Dujeu ${ }^{2} \&$ Hélène Nicolis ${ }^{3}$ \\ ${ }^{1}$ Free University of Brussels, ULB, Bruxelles, Belgium \\ ${ }^{2}$ School of Public Health, ULB, Bruxelles, Belgium \\ ${ }^{3}$ Child and Adolescent Department, La Plaine, SSM-ULB Bruxelles, Belgium
}

received: 9.9.2020;

revised: 12.5.2021;

accepted: 27.5.2021

\begin{abstract}
SUMMARY
Introduction: Denial of Pregnancy is a women's subjective lack of awareness of being pregnant. It can be partial (from 20 weeks but lifted before delivery) or complete (the women notice she's pregnant when labour starts). The prevalence is around 1/500 for partial denial and 1/2500 for complete denial. This article's aim is to review the literature broadly on the subject of pregnancy denial, its psychopathological hypothesis and the state of knowledge on the outcome for mothers and children.

Methods: 26 references have been selected bases on a research on pubmed database and through bibliography on the selected papers.

Results: Despite a lot of psychopathological hypothesis and some epidemiological studies, no objective knowledge can lead to know what kind of women will deny their pregnancy and how to prevent it. After all the studies on mother characteristics, it seems there are no "clear-cut" explanations on why a woman denies a pregnancy or what type of women could be at risk of denial. There are no official guidelines on how to manage the condition and care for the patient long term. The first elements of research on the developmental outcome for infant seem to show a delay in psychomotor skills and possible speech disorder. They have been significant advancement on the subject of children development after pregnancy denial in the last year but the psychological and developmental impact of pregnancy denial on children and mothers is still majorly unknown. With a clinical picture known for so long, to have so little objective information on how to manage it and on the possible consequences is surprising.

Conclusion: More research needs to be conducted to objectively know the long term effects of pregnancy denial on the whole family. International consensus should be found on the definition and care management of pregnancy denial.
\end{abstract}

Key words: pregnancy denial - children - development - outcome - psychopathology

\section{INTRODUCTION}

Pregnancy denial is still a difficult entity to understand. Despite more and more articles written on the subject, studies and objective knowledge lacks and there still is no official definition of pregnancy denial. Authors broadly agree that the primary definition of pregnancy denial is "a women's subjective lack of awareness of being pregnant" (Beier et al. 2006). Denial differs from concealment where the woman knows that she's pregnant and consciously hides it from her relatives. Denial and concealment belongs to an entity called "negated pregnancy" (Beier et al. 2006, Dayan \& Bernard 2013).

Inclusion criteria of the studies that examine pregnancy denial vary. French authors considers the end of the first trimester as the threshold for a pregnancy to be denied (Bayle et al. 2016). More commonly acknowledge is the idea that the denial takes place when a women is still unaware of her pregnancy after the $20^{\text {th }}$ week (Brezinka et al. 1994, Wessel 2002). A distinction is made between partial (from the $20^{\text {th }}$ week until labor) and complete pregnancy denial (where it stops when labor begins) (Bayle et al 2016).

Several authors tried to create sub-classification of pregnancy denial. Miller first made the distinction bet- ween psychotic and non-psychotic pregnancy denial (Miller 1990) then went on to propose three subtypes (Friedman et al. 2007, Miller 2003): affective, pervasive and psychotic.

In the first one, the woman knows she is pregnant but acts like she had no awareness of her state. She makes no changes in her life, nor interacts with the fetus. In a pervasive denial, the very existence of the pregnancy is unknown to the mother. Symptoms and physical signs of pregnancy may be absent (no weight gain, no amenorrhea, no nausea...) or when present, are attributed to other causes. Partners and family also fail to recognize the pregnancy. More rarely, the denial persist until term or even until delivery, the women being surprised by the pain of childbirth. This can lead to home deliveries and, in very severe cases, the denial persists after delivery and ends with neonaticide (Dayan \& Bernard 2013, Spinelli 2001). Most research focuses on this type of denial and it's the subject of this document.

Psychotic denial is specific to psychotic patients and the awareness of pregnancy changes all the time. Signs of pregnancy occur and the relatives of the patients are aware of them. Sometimes, the patient denies her state and interprets symptoms in a delusional way. 
For decades, researchers have proposed, without result, definitions and classifications with the objective to make pregnancy denial an official illness in the international classifications (DSM and ICD) (Beier et al. 2006, Seguin et al. 2013, Kenner \& Nicolson 2015). It is worth noting that pseudocyesis is already in the DSM (Kenner \& Nicolson 2015).

The first described case of unrecognized pregnancy is reported by Estienne Esquirol in 1838 (Seguin et al. 2013). The first review about denial of pregnancy was conducted in England by Gould and Pyle in 1898 (Dayan \& Bernard 2013, Seguin et al. 2013) about 12 cases of women who underwent what they called "unconscious pregnancy" and they accurately describe the lack of usual symptoms and physical changes and concludes epidemiologically that the women were "primiparous or multiparous, young or mature, most of them married and exempt from mental illnesses".

Few epidemiological studies have been conducted on this topic. In 2002, Wessel (Wessel 2002) conducted the first large scale prospective, multicentric study of the prevalence of pregnancy denial ( from 20 weeks). They found that 1 in 475 pregnancies were denied globally and that 1 in 2455 pregnancies were denied until delivery (Wessel 2002).

In the others, smaller-scaled or retrospective studies, the range of prevalence of pregnancy denial (from 20 weeks) was between 1 case/300 pregnancies and 1/500. A large variety was observed for complete pregnancy denial (until the delivery), the range was between 1 case/500 pregnancies and 1/2500 (Brezinka et el. 1994, Nirmal et al. 2006, Friedman et al. 2007, Kenner \& Nicholson 2015, Schultz \& Bushati 2015, Bayle et al. 2016, Simermann et al. 2018).

It seems clear that the notion that pregnancy denial is a rare event is wrong.

Finally, information about pregnancy denial's impact on the infants born after being denied and their subsequent development are excessively scarce.

This article's aim is to review the literature broadly on the subject of pregnancy denial, what psychopathological hypothesis currently exists and the state of knowledge on the short and long-term consequences that could arise for the mothers and children born in this circumstance.

\section{METHODS}

The authors used PubMed Medline database with MeSH (Medical Subject Heading) searching the terms "denial" AND "pregnancy", then they tried to precise some subject by adding to the search builder AND "pregnancy outcome" followed by AND "Infant". The relevant articles were selected based on their abstracts. References given in articles were also scrutinized. They included papers published in English and French over the past 30 years. Case reports were excluded. Considering that the term "neonaticide" (the killing of infants at birth or soon after) seemed to appear regularly linked to denial of pregnancy, the authors decided to add it to search builder as well with AND "infanticide" (only existing MeSH term). This PubMed search lead to 23 sources. The authors also researched the Cochrane library, to no avail. Books were selected, based on the bibliography and from recommendation from senior child psychiatrist. This method lead to the 26 selected references.

\section{RESULTS}

\section{Psychopathological hypothesis and mother characteristics}

11 of the references researched criteria that could predict or looked into hypotheses that could explain pregnancy denial: 1 was a prospective case-control observational study, 6 were retrospective observational study, 2 were literature reviews and 2 were based on the experience of one professional expert.

Wessel, in 2007, continued his researched started in 2002 with the prospective prevalence study. He wanted to know more about the characteristics of the women who deny their pregnancy and whether they had a common ground (Wessel et al 2007). He researched socio-demographic variables among the group of 65 women and compared them with the national birth register. The age range went from 15 to $44,80 \%$ of them had a stable partner and $80 \%$ had completed their education. $1 / 3$ of the women were primiparous. 3 women had schizophrenia, 2 showed signs of personality disorder, 3 showed decreases in intelligence (but no test was performed) and 5 had a substance abuse record. The authors concludes that psychotic denial is the minority of case (only 5\%) and that their study rules out a lot of "probable risk factor" that had been previously proposed: younger age, social isolation, low intelligence, low socio-economic status and naiveté about bodily function were all thought to be characteristic of women who denied their pregnancy but was not supported by this study: An "unambiguous typology of pregnancy deniers" could not be described.

6 retrospective observational studies found similar results and looked into psychopatological hypotheses. Friedman researched the characteristics of women with pregnancy disavowal and found the same "counterintuitive" results as Wessel (Friedman et al. 2007): the women were predominantly over 18 , multigravidas and with no criteria of social isolation. Contrary to other findings, this study found history of abuse in only a few women (but noted that maybe it had not been thoroughly researched) and could not identify any psychiatric illness but mentions the lack of referral to psychiatrist. Nirmal also studied women characteristics and found that $21 \%$ of them were married, $58 \%$ were multiparous of whom $8 \%$ had had a caesarean section in the past. $8 \%$ had a previous history of a concealed pregnancy (Nirmal et al. 2006). Schultz in 2015 found similar results (Schultz et al. 2015). 
For Brezinka, denial can be a defense mechanism used in healthy individuals under unusually severe stress (Brezinka et al. 1994). He assessed 27 women who had pregnancy disavowal: $52 \%$ of them didn't meet any psychopathological criteria, 4 patients had a history of depression, 4 had a personality disorder and 3 had a mild mental retardation. Psychosocial stressors were found before the pregnancy in all women, especially problems with their partners.

Beier, in 2006, compared a group of women with pregnancy denial and one who commited neonaticide (Beier et al. 2006). The first group came from the population study by Wessel in 2002, but they included the women with concealed pregnancy. They advocated creating a new category in the DSM: reproductive disorder. They then proceeded to bring together denied and concealed pregnancy under the new concept of "negated pregnancy", claiming that they are not separate entities but "different intensity level of flawed inner psychological rationalization of pregnancy that may have very different reasons". Beier continues by saying that if the negation is internal it becomes denial but if external, concealment. He moreover cites Kaplan who declares that the psychopathological mechanism that explains non-psychotic pregnancy disavowal is conversion (Kaplan \& Grotowski 1996). He also formulates the hypothesis that projective identification may be a reason for the lack of diagnosis when pregnant women in denial seek help from their doctor for an apparently unrelated problem. Regarding neonaticide, Beier explains that the characteristics of women who denies and commits neonaticide are not very different: Neonaticide should be seen as the result of "extreme final paths of (psychological) coping with pregnancy - in the sense of a continually and completely negated (denied or concealed) pregnancy"(Beier et al. 2006).

Seguin, in her doctoral thesis, studied the psychological structure of women who denied their pregnancy using projective test (Rorschach and TAT) (Bayle and al. 2016). The study showed a majority of nevrotic structure with rigid defense mechanism of an obsessional nature and a tendency to avoid conflict. The women in her research had difficulties identifying with a feminine figure and couldn't internalize a quality maternal model, they showed some narcissistic weaknesses and problems to elaborate loss and depressivity.

In a pregnancy denial review, Spielvogel found history of sexual abuse in childhood and history of substance abuse (Spielvogel \& Hohener 1995). The absence of psychiatric history of the women leads them to the hypothesis that pregnancy denial was a form of adjustment disorder.

In 2011, Sandoz published a review proposing a cybernetic approach to the question of the silhouette changing when denial is lifted (Sandoz 2011). He claimed that announcing the pregnancy acts as an input signal to the body regulation mechanism that leads to a body change (output signal). He suggests a reactive homeostasis that regulates the bodyshape in an abnormal way because of an "unconscious brain's mechanism to escape paradoxical realities". The quick change of silhouette would follow the dissolution of the paradoxical situation.

The 2 last sources came up with psychopathological hypotheses based on their professional experiences. Bonnet conducted a survey to understand the motivations of 22 women who wanted to give birth anonymously and give away the child (Bonnet 1993). Several of them had experienced pregnancy denial. For primiparous women, she talked about "unthinkable pregnancy": they couldn't psychologically link sexual intercourse and pregnancy. Some also had history of sexual trauma and abuses in their childhood. For the multiparous women, Bonnet found stress factor in their recent history, especially with partners (as Brezinka did). From psychoanalysis sessions with those patients, she found a lot of violent thoughts and impulses towards the fetus. She concluded that denial might also be a defense mechanism against these aggressive urges.

Sophie Marinopoulos, a French psychoanalyst hypothesized that although denied pregnancy are not consciously wanted, they are unconsciously desired. She noted that when denial stops in the $2^{\text {nd }}$ trimester and women starts therapy, unresolved oedipien conflict can be found with fathers who couldn't authorize their daughter to enter an affective life of they own (Marinopoulos 2007). When denial is complete, Marinopoulos states that the precocious parents-baby relationship may be problematic.

\section{Psychological consequences}

\section{Mother's Outcome}

6 references gave insight into what the consequence of pregnancy denial could be for mothers: the wessel's prospective study, the 3 retrospective observational study from Brezinka, Nirmal and Friedman, 1 literature review from Jenkins and an article relating their own experience from Stotland.

Patient reaction when discovering their pregnancy state is varied and can go from surprised but content reaction to neonaticide in extreme cases (Stotland 1998). As pointed by Jenkins, denial incidence decrease over the gestation period (1/475 at 20GA and 1/2500 at term) showing that the condition is transient, but there is no information on what happens next (Jenkins et al. 2011). Jenkins states that the post-partum period is more at risk of emotional disturbance for women who did not know they were pregnant but doesn't specify. Nirmal reported that there were no post-partum depression or psychosis observed in his cohort of 24 women but admitted he did not know whether counseling had been offered to any of these patients (Nirmal et al. 2006)

Brezinska is one of the only author who gave some perspective on emotional reactions when denial was lifted: 2 women developed psychotic symptoms, 5 women responded with conflict reactions (running away, doing very hard work) and the other women had stress 
reactions with fear, shock or insecurity for a short period of time. The extent and the duration of these reactions was dependent on the social and emotional support experienced (Brezinka et al. 1994). Wessel added that women reported feeling guilty for not giving the best care to their baby while they were unknowingly pregnant (Wessel et al. 2007).

It is also stated that some women can experience dissociative symptoms at delivery if the denial was complete (Friedman et al. 2007, Spinelli 2001).

\section{Children's Outcome}

6 articles gave information about outcome for babies born after a pregnancy denial: 3 retrospective observational study briefly mentioned it, 1 review of neonaticide and 1 restrospective observational study discussed the link between neonaticide and pregnancy denial and 2 very recent prospective studies researched exclusively children's outcome avec pregnancy denial.

From the 3 retrospective studies, it seems that only a minority of children ends up in foster care or adopted. In the study of Brezinska, only 1 in 23 children was given to foster parents (Brezinka et al 1994). Of the 69 babies delivered in Beier's paper, 13 were adopted and 1 went in foster care (Beier et al. 2006). In Schultz's research, 2 in 5 babies were adopted (Schultz and al 2015).

In Simermann's prospective study, the Mother and Child Welfare service was aware of the pregnancy denial and $59 \%$ of the children were monitored, $20 \%$ of whom were under close scrutiny. Four children were in foster care and two were placed temporarily (Simermann et al. 2018).

To the very extreme end of the outcome spectrum stands neonaticide. Althought pregnancy denial and neonaticide are often talk about together in scientific literature or in the media, the rate of pregnancy denial ending in neonaticide seems to be extremely low (While the rate of neonaticide that follows a pregnancy denial seems to be high (Friedman \& Resnick 2009) but even that view is controversial (Vellut et al. 2012)). Only 1 case of neonaticide was found in the first Wessel study (Wessel et al. 2003) but Vellut demonstrated that it was not possible to calculate the frequency of the association between pregnancy denial and neonaticide given that studies on deliveries cannot be exhaustive since they do not take into account deliveries unassisted by healthcare professionals, including clandestine deliveries followed by neonaticide (Vellut et al. 2012).

Brezinska dedicates only a small section on follow up (Brezinka et al 1994): According to him, no babies were mistreated or showing signs of emotional abuse. He concluded that there was no reason to place the children in foster care as a rule after pregnancy denial.

The aim of Simermann's prospective exploratory study was to assess whether pregnancy denial has an impact on height and weight, psychomotor development, and possible subsequent pathologies in 51 children born after pregnancy denial (Simermann et al.
2018). Full-term infants born after partial or complete pregnancy denial were included. They collected data related to the development of the infants: neonatal period, at 9 months, at 2 years and a questionnaire of the current state of the child (aged between 2 and 7 years old). The child's psychomotor development was assessed according to the Denver Developmental Screening Test and allowed to appreciate both gross and fine motor skills as well as language and social contact. Babies were born with proportional growth restriction but by 9 month they had catched-up on their growth. The infant mortality rate was $5 \%$ in the total number of children (4/75) which is significantly higher than in the total population (the perinatal mortality rate of infants in France in 2010 was $1.9 \%$ ) (Simermann et al. 2018) . 10 children out of the 51 showed pathologies. Out of the 41 cases who answered the "current state" questionnaire: $17 \%$ were being treated by a speech therapist, $2 \%$ by a physiotherapist, and $10 \%$ by a psychologist. Regarding psychomotor development, the records at 9 and 24 months showed that about $15-20 \%$ of the children suffered from developmental problems and it was getting worse as they grew older. In the final evaluation of the children's current state of health, they noted an increase of developmental problems with $31 \%$ of the children concerned, half of which were language disorders. Simermann points that nearly $30 \%$ of the children had delayed psychomotor development. This delay prevailed at 9 months in fine motor activities (with only $52 \%$ of the children pointing the finger), but language level was the main problem around 2 years. They conclude that pregnancy denial probably has developmental consequences and that the rate of psychomotor delay indicates that thorough follow-up was needed.

In 2019, Auer published the protocol of a research presently taking place (Auer et al. 2019). The main objective of her multicentric case-control 18 month long prospective study is to explore the link between pregnancy denial and child development: infant attachment pattern, dyads early interactions and child early development.

They hypotheses that the likelihood of pregnancy denial would be higher if the mothers themselves had an insecure attachment pattern. They believe that the absence of the usual 9-month period needed for psychological elaboration could have an impact on the quality of mother-child interactions. The study's followup is 20 months and each dyad will receive 6 visits with different test and measurements in that time period. They will assess mother's anxiety level, perceived social support, postnatal depression and attachment style. The babies will be assessed for their relational behavior and their psychomotor skills. At 18 months, the child attachment pattern will be evaluated.

\section{Care and Treatment}

5 articles briefly mentioned how to care for women who undergo denial of pregnancy. 
Table 1. Overview of the studies

\begin{tabular}{|c|c|c|c|c|}
\hline Year & Author(s) & Type of study & Number of subjects & Informations mainly on \\
\hline 1993 & Bonnet & Expert opinion & 22 & Psychopathological hypothesis \\
\hline 1994 & Brezinka et al. & Retrospective & 27 & $\begin{array}{l}\text { Incidence; psychopathological hypothesis; } \\
\text { mother and children's outcome }\end{array}$ \\
\hline 1995 & $\begin{array}{l}\text { Spielvogel \& } \\
\text { Hohener }\end{array}$ & Review & NA & Psychopathological hypothesis \\
\hline 1998 & Stotland & Expert opinion & NA & Mother's outcome \\
\hline 2002 & Wessel & Prospective multicentric & 62 & Incidence \\
\hline 2003 & Wessel et al. & Prospective multicentric & 65 & Obstetical outcome \\
\hline 2006 & Beier et al. & Retrospective & 78 & Psychopathological hypothesis \\
\hline 2006 & Nirmal et al. & Retrospective & 24 & $\begin{array}{l}\text { Incidence; mother's characteristics; } \\
\text { mother's outcome }\end{array}$ \\
\hline 2007 & Friedman et al. & Retrospective & 61 & $\begin{array}{l}\text { Incidence; psychopathological hypothesis; } \\
\text { mother's characteristics; mother's outcome }\end{array}$ \\
\hline 2007 & Wessel et al. & Prospective multicentric & 65 & $\begin{array}{l}\text { Psychopathological hypothesis; mother's } \\
\text { characteristics }\end{array}$ \\
\hline 2007 & Marinopoulos & Expert opinion & NA & Psychopathological hypothesis \\
\hline 2009 & $\begin{array}{l}\text { Friedman \& } \\
\text { Resnick }\end{array}$ & Review & NA & Children's outcome (neonaticide) \\
\hline 2011 & Jenkins et al. & Review & NA & $\begin{array}{l}\text { Incidence, psychopathological hypothesis, } \\
\text { mother's outcome }\end{array}$ \\
\hline 2011 & Sandoz & Review & NA & Psychopathological hypothesis \\
\hline 2012 & Velut et al. & Retrospective & 32 & Children’s outcome (neonaticide) \\
\hline 2015 & Schultz \& Bushati & Retrospective & 5 & Incidence; mother's characteristics \\
\hline 2016 & Bayle & $\begin{array}{l}\text { Book: mentions Seguin's } \\
\text { retrospective doctoral thesis }\end{array}$ & $\mathrm{U}$ & Psychopathological hypothesis \\
\hline 2018 & Simermann et al. & Prospective & 51 & Incidence; children's outcome \\
\hline 2019 & Auer et al. & Prospective (protocol) & NA & Children's outcome \\
\hline
\end{tabular}

The mothers are sometimes referred to psychiatrist or psychologist after the denial is lifted (Brezinka et al. 1994, Friedman \& Resnick 2009) and some authors recommend it: "Counseling has to integrate comprehensive psychiatric and obstetrical care including pharmacotherapy, supportive psychotherapy and evaluation of the patients' parenting skills and support network to assess whether she is able to keep her baby" (Brezinka et al. 1994).

But referral to counseling seems rare: Jenkins cites the research of Moyer stating than the rate of referral to a psychiatrist after a pregnancy denial is less than $10 \%$ (Jenkins et al. 2011) and Nirmal admits that it was never requested (Nirmal et al. 2006).

Jenkins, points the utmost importance of a good liaison psychiatry in the maternity ward and of interdisciplinarity (obstetrician, pediatricians and psychiatrist) to take care of those patients (Jenkins et al. 2011).

Some authors also point out that the existence of pregnancy denial should be wider known among healthcare professionals to help diagnose and lift pregnancy denial early on. Indeed, the prevention of lack of antenatal care relies on health professionals (pediatrics, emergency medicine, internal medicine and family practice) awareness of the problem (Friedman et al. 2007). They should have a higher index of suspicion of pregnancy when women consult with symptoms that could be explained by a state of pregnancy (Wessel et al. 2007) (Table 1).

\section{DISCUSSION}

Pregnancy denial is a women's subjective lack of awareness of being pregnant. It can be partial (from 20 weeks but lifted before delivery) or complete (the women notice she's pregnant when labour starts). Despite a lot of psychopathological hypothesis and some epidemiological studies, no objective knowledge can lead to know what kind of women will deny their pregnancy and how to prevent it. "Pregnancy denial is a heterogeneous condition with different meanings and different psychiatric diagnoses in different women" (Brezinka et al. 1994). So when confronted with this situation, professionals should try to understand why "this woman with this partner at this time denies this pregnancy" in a case- by-case approach (Beier et al. 2006).

Most of the studies of this review are about epidemiological evidence and characteristics of the women to whom it happens, but the conclusions from the first known review on the subject conducted by Gould and Pyles in 1898 seems to still stand today 
(Dayan \& Bernard 2013, Seguin et al. 2013): there is no precise type of women who denies their pregnancy.

On the outcome subject, there is no long term follow-up research looking into how the women adapts to the situation or if they suffer from post-partum wide range of pathopsychological symptoms (depression, psychosis, PTSD...etc.).

This review was first undertaken in 2015 when information on the children's outcomes after pregnancy was nearly inexistent and often linked to neonaticide whereas that consequence seems to be quite rare. The only time children's outcome was mentioned was in 1994 Brezinka's paper stating the children were not mistreaded (Brezinka et al. 1994) but no information is given on how those facts were collected or how the children were evaluated. They have been significant advancement on the subject of children development after pregnancy denial recently but it arrives in the 2018 Simermann's paper, 24 years after Brezinska's study (Simermann et al. 2018). It's interesting to note that the first information available suggests that language disorder seems to be one of the main problems of denied children. Nevertheless, the psychological and developmental impact of pregnancy denial on children is still majorly unknown. A major prospective study is currently (and finally) taking place on the subject (Auer et al. 2019). The results of this research may help better understand the nature of pregnancy denial and the children's outcome, effectively helping professionals to come up with guidelines for prevention and treatment as there presently is no consensus on how to manage pregnancy denial.

With a clinical picture known for so long, to have so little objective information on how to manage it and on the possible consequences is surprising. It isn't farfetched to say that society has a whole, and the healthcare communities in particular, seems to have suffered from denial of the denial. This statement can moreover be found in Friedmann's 2007 article: "the lack of attention to the phenomenon of pregnancydenial mirrors the silent stance of these patients." (Friedman et al 2007).

As is often the case in perinatology, the major hole in every study cited in this review is how pregnancy denial affects the fathers and what the consequences on the father-child relationship are. Since according to the multiple studies, most of the women who denies have partners, and sometimes are also multiparous, it should be self-evident that they are going to be consequences for the fathers, the couple and for the whole family.

\section{CONCLUSION}

The existence of pregnancy denial has been known for more than a century now but the subject is still vastly under researched. It still isn't an official diagnosis in any of the International Classification (DSM V or ICD-10) even when several authors have raised awareness on that fact and propose a classification and a name for it (Beier et al 2006, Miller 2003).
More studies will have to be undertaken to fully understand the multiple impacts of pregnancy denial on every person concerned by it: the mother, the baby but also the rest of the family depending on the situation. Furthermore, the main focus should presently be to create an international consensus and guidelines on how to take care and manage the patient affected by a pregnancy denial, be it adults or children.

\section{Limit of the review}

The number of pertinent references on the subject of pregnancy denial is rather low (26) and the weight of each article is very different so it was difficult to compare them together. A minority of articles are prospective and case-control but they are discussed more thourougly in this paper, most of the references are retrospective observational study and literature review and they are explained as such. The clinical impression papers completes the clinical picture of pregnancy denial and tackles different aspect of the issue so they've been included in this review but not given much weigh.

\section{Acknowledgements: None.}

\section{Conflict of interest: None to declare.}

\section{Contribution of individual authors:}

Donatella Kettlewell: literature searches and analyses, manuscript writing.

Maud Dujeu: proofreading, structure adjustments propositions, highlights of the important themes.

Hélène Nicolis: supervision of the whole work, guidance, proofreading.

\section{References}

1. Auer J, Barbe C, Sutter AL, Dallay D, Vulliez L, Riethmuller D et al.: Pregnancy denial and early infant development: a case-control observational prospective study. BMC Psychol 2019; 7: 22-29

2. Bayle B: Le déni grossesse, un trouble de la gestation psychique. La vie de l'enfant. Eres, 2016

3. Beier KM, Wille R, Wessel J: Denial of pregnancy as a reproductive dysfunction: A proposal for international classification systems. J Psychosom 2006; 61:723-730

4. Bonnet C: Adoption at birth: Prevention against abandonment or neonaticide. Child Abus Negl 1993; 17:501-513

5. Brezinka C, Brezinka C, Biebl W, Kinzl J: Denial of pregnancy: Obstetrical aspects. J Psychosom Obstet Gynecol 1994; 15:1-8

6. Dayan $J \&$ Bernard A: Déni de grossesse, infanticide et Justice. Ann Med Psychol 2013; 171:494-498

7. Friedman SH, Heneghan A, Rosenthal M: Characteristics of Women Who Deny or Conceal Pregnancy. Psychosomatics 2007; 48:117-122

8. Friedman SH \& Resnick PJ: Neonaticide: Phenomenology and considerations for prevention. Int J Law Psychiatry 2009; 32:43-47 
9. Jenkins A, Millar S, Robins J: Denial of pregnancy - a literature review and discussion of Ethical and legal issues. JR Soc Med 2011; 104:286-291

10. Kaplan $R$ \& Grotowski T: Denied pregnancy. Aust $N$ Z J Psychiatry 1996; 30:861-863

11. Kenner WD \& Nicolson SE: Psychosomatic Disorders of Gravida Status: False and Denied Pregnancies. Psychosomatics 2015; 56:119-128

12. Marinopoulos S: Le déni de grossesse. yapaka.be. 2007

13. Miller LJ: Psychotic Denial of Pregnancy: Phenomenology and Clinical Management. Hop Commnity Psychiatry 1990; 41:1233-1237

14. Miller LJ: Chapter 5: denial of pregnancy. In Spinelli MG: infanticide: Psychosocial and Legal Perspectives on Mothers Who Kill. American psychiatric publishing, 2003

15. Nirmal D, Thijs I, Bethel J, Bhal PS: The incidence and outcome of concealed pregnancies among hospital deliveries: An 11-year population-based study in South Glamorgan. J Obstet Gynaecol 2006; 26:118-121

16. Sandoz P: Reactive-homeostasis as a cybernetic model of the silhouette effect of denial of pregnancy. Med Hypotheses 2011; 77:782-785

17. Schultz MJ \& Bushati T: Maternal physical morbidity associated with denial of pregnancy. Aust New Zeal J Obstet Gynaecol 2015; 55:559-564
18. Seguin S, Golse B, Apter G: Déni et négation de grossesse: une revue de la littérature. Psychiatr Enfant 2013; 56:267-292

19. Simermann M, Rothenburger S, Auburtin B, Hascoët JM: Outcome of children born after pregnancy denial. Arch Pediatr 2018; 25:219-222

20. Spielvogel AM \& Hohener HC: Denial of pregnancy: a review and case reports. Birth 1995; 22:220-226

21. Spinelli MG: A systematic investigation of 16 cases of neonaticide. Am J Psychiatry 2001; 158:811-813

22. Stotland NE: Denial of pregnancy. Prim Care Update Ob Gyns 1998; 5:247-250

23. Vellut N, Cook JM, Tursz A: Analysis of the relationship between neonaticide and denial of pregnancy using data from judicial files. Child Abus Negl 2012; 36:553-563

24. Wessel J: Denial of pregnancy: population based study. Bmi 2002; 324:458-458

25. Wessel J, Endrikat J, Buscher U: Elevated risk for neonatal outcome following denial of pregnancy: results of a one-year prospective study compared with control groups. J Perinat Med 2003; 31:29-35

26. Wessel J, Gauruder-Burmester A, Gerlinger C: Denial of pregnancy - Characteristics of women at risk. Acta Obstet Gynecol Scand 2007; 86:542-546

Correspondence:

Donatella Kettlewell, MD

Free University of Brussels, ULB

La Plaine SSM-ULB: Campus de la Plaine, Boulevard du Triomphe, accès $n^{\circ} 2$, bâtiment $H B, 1050$ Bruxelles, Belgium

E-mail:donakettle@hotmail.com 